\title{
Enhanced Thermal Conductivity of Carbon Nanotube Arrays by Carbonizing Impregnated Phenolic Resins
}

\author{
Dongmei Hu ${ }^{1}$, Hongyuan Chen ${ }^{1}$, Zhenzhong Yong ${ }^{1}$, Minghai Chen ${ }^{1}$, Xiaohua Zhang ${ }^{1}$, Qingwen Li ${ }^{1}$, \\ Zhen Fan ${ }^{2,3}$, Zhihai Feng ${ }^{2,3}$ \\ ${ }^{1}$ Key Laboratory of Nano-Devices and Applications, Suzhou Institute of Nano-Tech and Nano-Bionics, Chinese Academy of Sci- \\ ences, Suzhou, China; ${ }^{2}$ State Key Laboratory of Powder Metallurgy, Central South University, Changsha, China; ${ }^{3}$ National Key \\ Laboratory of Advanced Functional Composite Materials, Aerospace Research Institute of Materials and Processing Technology, \\ Beijing, China. \\ Email: fengzhh2006@sina.com
}

Received June $8^{\text {th }}, 2013$; revised July $9^{\text {th }}, 2013$; accepted July $18^{\text {th }}, 2013$

Copyright (C) 2013 Dongmei Hu et al. This is an open access article distributed under the Creative Commons Attribution License, which permits unrestricted use, distribution, and reproduction in any medium, provided the original work is properly cited.

\begin{abstract}
A carbonization method is reported to improve the thermal conductivity of carbon nanotube (CNT) arrays. After being impregnated with phenolic resins, CNT arrays were carbonized at a temperature up to $1400^{\circ} \mathrm{C}$. As a result, pyrolytic carbon was formed and connected non-neighboring CNTs. The pyrolysis improved the room temperature conductivity from below $2 \mathrm{~W} / \mathrm{m} \cdot \mathrm{K}$ up to 11.8 and $14.6 \mathrm{~W} / \mathrm{m} \cdot \mathrm{K}$ with carbonization at $800^{\circ} \mathrm{C}$ and $1400^{\circ} \mathrm{C}$, respectively. Besides the light mass density of $1.1 \mathrm{~g} / \mathrm{cm}^{3}$, the $\mathrm{C} / \mathrm{C}$ composites demonstrated high thermal stability and a higher conductivity up to $21.4 \mathrm{~W} / \mathrm{m} \cdot \mathrm{K}$ when working at $500^{\circ} \mathrm{C}$.
\end{abstract}

Keywords: Carbon Nanotube; Phenolic Resin; Pyrolysis; Thermal Conductivity

\section{Introduction}

Experimental and theoretical studies have shown that the thermal conductivity of a carbon nanotube (CNT) is up to several thousand $\mathrm{W} / \mathrm{m} \cdot \mathrm{K}[1-4]$, showing great potentials in the thermal management area. Many studies have been reported on the use of dispersed CNTs as thermal conducting fillers in a polymer matrix, whose thermal conductivity can be significantly improved by $65 \%-125 \%$ even at a small loading of CNTs [5-7]. However, these $\mathrm{CNT} /$ polymer composites still had a much lower thermal conductivity than predicted, possibly due to the interfacial resistances between the CNTs and matrix or between contacting tubes, modification of the phonon conduction in CNT by the matrix, formation of voids in composites, and structural defects of CNTs, as briefly reviewed by Marconnet et al. very recently [8].

Different from the random orientation of dispersed CNTs, the aligned feature of CNT arrays offers another solution to develop thermal management materials with a unidirectionally high conductivity. The thermal conductivity of CNT arrays was reported to range from several to hundreds of $\mathrm{W} / \mathrm{m} \cdot \mathrm{K}$ [9-13]. However, the as-produced CNT arrays were difficult to use due to the weak mechanical property in the direction perpendicular to the alignment. In order to improve the mechanical and thermal properties or to decrease the contact resistance of a CNT array, metal filling and/or coating $[14,15]$, polymer impregnation using silicone rubber S160 [16], polydimethyl siloxane [17], or epoxy [8,18], covalent bonding at contact interfaces [19], and graphitization inside the array $[20,21]$ have been designed.

The purpose of this study, based on the method of polymer impregnation, is to develop $\mathrm{C} / \mathrm{C}$ composite thermal management materials by carbonizing phenolic resins within multiwalled CNT arrays, and to investigate the thermal conductivities at high working temperatures. Carbonization converted the resins into pyrolytic carbon and thus adhered non-neighboring CNTs. Owing to the pathways to conduct heat between CNTs, the thermal conductivity was significantly improved. For instance, by using a carbonization temperature of $1400^{\circ} \mathrm{C}$, the thermal conductivity was up to $14.6 \mathrm{~W} / \mathrm{m} \cdot \mathrm{K}$, nearly quintuple that of the raw CNT arrays. The $\mathrm{C} / \mathrm{C}$ composites exhibited a higher conductivity of $21.4 \mathrm{~W} / \mathrm{m} \cdot \mathrm{K}$ when working at $500^{\circ} \mathrm{C}$. The composites had a low mass density $(1.1$ $\mathrm{g} / \mathrm{cm}^{3}$ ) and were stable up to about $550^{\circ} \mathrm{C}$ in air and about $1000^{\circ} \mathrm{C}$ in $\mathrm{Ar}$, leading to possible applications at extreme conditions. 


\section{Experimental}

A floating catalyst chemical vapor deposition method was used to grow the multiwalled CNT arrays [22], due to the ability to produce long length CNTs. Scanning electron microscopy (SEM) and transmission electron microscopy (TEM) images show that the array height was up to $1.8 \mathrm{~mm}$ and the tube diameter was $>30 \mathrm{~nm}$, see Figures 1(a) and (b). As shown in Figure 1(c), the large ratio between the Raman intensities of $G$ and $D$ peaks, as well as the high 2D Raman peak, indicated that the CNTs had high crystallinity. These features had both advantages and shortages; the long length made the processing easy and the perfect CNT structure allowed long phonon mean free paths, while only the outermost layers of the CNT played roles in heat transfers.

To prepare the $\mathrm{C} / \mathrm{C}$ composites, aerospace-grade phenolic resins (from Prof. T. Zhao's group, Institute of Chemistry, Chinese Academy of Sciences) were first introduced into CNT arrays by a vacuum impregnation method at room temperature for $20 \mathrm{~min}$. After this, the arrays were cured at $100^{\circ} \mathrm{C}$ for $6 \mathrm{~h}$, at $120^{\circ} \mathrm{C}$ for $2 \mathrm{~h}$, and finally at $180^{\circ} \mathrm{C}$ for $4 \mathrm{~h}$. Then the cured samples were carbonized in argon for $2 \mathrm{~h}$ at a designed temperature ranging from $200^{\circ} \mathrm{C}$ to $1400^{\circ} \mathrm{C}$.

The thermal conductivity $(\kappa)$ of $\mathrm{C} / \mathrm{C}$ composites can be calculated according to $\kappa=\alpha \rho C_{p}$, where $\alpha$ is the thermal diffusivity, $\rho$ the mass density, and $C_{p}$ the specific heat capacity. In the present study, a Laser Flash Apparatus LFA-457 (Netzsch-Gerätebau GmbH, Selb, Germany) and an STD-2960 thermal analyzer (TA Instruments, New Castle, DE,USA) were used to measure $\alpha$ and $C_{p}$, both in $\mathrm{Ar}$ atmosphere, while $\rho$ was calculated according to the dimensions and total mass.

\section{Results and Discussion}

By measuring the mass change after carbonization at $800^{\circ} \mathrm{C}-1400^{\circ} \mathrm{C}$, the weight fraction of CNT in the final composites was calculated to be $\sim 30 \mathrm{wt} \%$. This means that the empty spaces between the CNTs were well impregnated by the polymers, see Figure 2 where SEM images of one pure CNT array and three carbonized $\mathrm{C} / \mathrm{C}$ composites (at $500^{\circ} \mathrm{C}, 700^{\circ} \mathrm{C}$, and $1400^{\circ} \mathrm{C}$ ) are shown. Notice that the CNT alignment was no longer straight
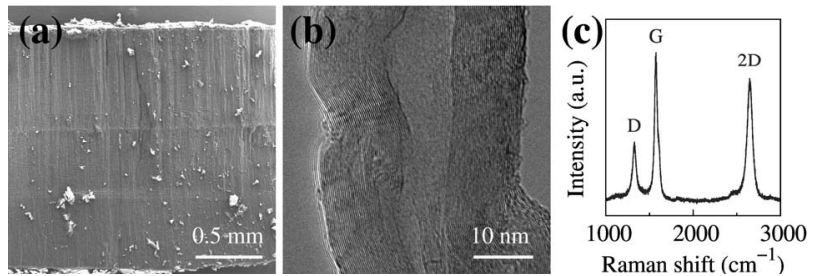

Figure 1. (a) SEM image of a $1.8 \mathrm{~mm}$ thick CNT array; (b) TEM image of a CNT; (c) Raman spectrum for a raw CNT array.
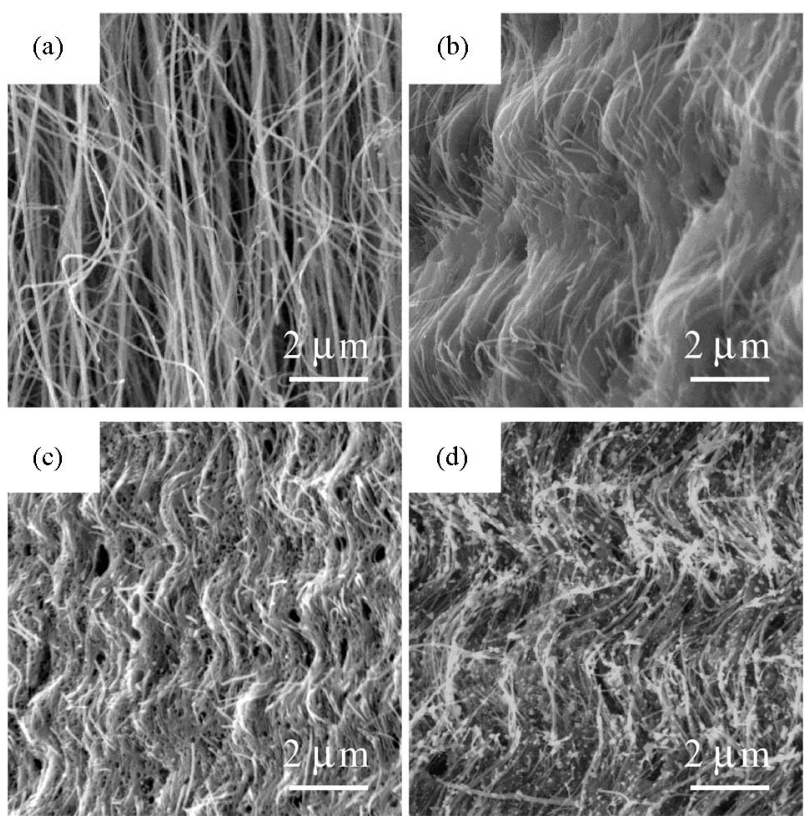

Figure 2. SEM images of a pure CNT array (a) and three $\mathrm{C} / \mathrm{C}$ composites carbonized at 500,700 , and $1400^{\circ} \mathrm{C}$ (b)-(d), respectively.

after the impregnation and kept to be curled after the curing and carbonization, because the vacuum condition usually applied a certain pressing on the composites.

The introduction of phenolic resins or carbonized pyro lytic carbon had strong influences on the thermal properties. Figure 3(a) shows the results of $\rho$ and $\kappa$ as functions of carbonization temperature, and typical values of $\alpha, \rho, C_{p}$, and $\kappa$ are also given in Table $\mathbf{1}$ for five selected samples including a pure CNT array and phenolic matrix as well. Generally, $\rho$ decreased with increasing the temperature because the pyrolysis reactions continuously took place between phenolic resins by forming and removing small molecules like $\mathrm{H}_{2} \mathrm{O}, \mathrm{CH}_{4}, \mathrm{H}_{2}$, and $\mathrm{CO}$ $[23,24]$. The sharp decrease in $\rho$ started at a temperature within $400^{\circ} \mathrm{C}-500^{\circ} \mathrm{C}$, indicating the beginning stage of pyrolysis. When the temperature was as high as $700^{\circ} \mathrm{C}$ $800^{\circ} \mathrm{C}$, the mass loss became much smaller because the evolution of $\mathrm{CH}_{4}, \mathrm{H}_{2}$, and $\mathrm{CO}$ nearly stopped [23]. Such pyrolysis converted the glue-like phenolic matrix into pyrolytic carbon, as shown in Figures 2(b) and (c). The covalent cross-linking between the resins by pyrolysis, and by curing as well, obvious enhanced the capacity to conduct heat between non-neighboring CNTs, as reflected by the magnitude of $\alpha$. For a pure CNT array $\alpha=$ $9.13 \mathrm{~mm}^{2} / \mathrm{s}$ and for a pure phenolic matrix $\alpha=0.16$ $\mathrm{mm}^{2} / \mathrm{s}$. When they were hybrid, $\alpha$ became $1.2 \mathrm{~mm}^{2} / \mathrm{s}$ due to a simple mixing rule, and, most importantly, higher than $15 \mathrm{~mm}^{2} / \mathrm{s}$ after being carbonized at high temperatures. This value was comparable to that of iron (23 $\left.\mathrm{mm}^{2} / \mathrm{s}\right)$. The change in $\alpha$ played the key role in improving $\kappa$, so that $\kappa$ was increased from $<2$ up to $11.8-14.6$ 

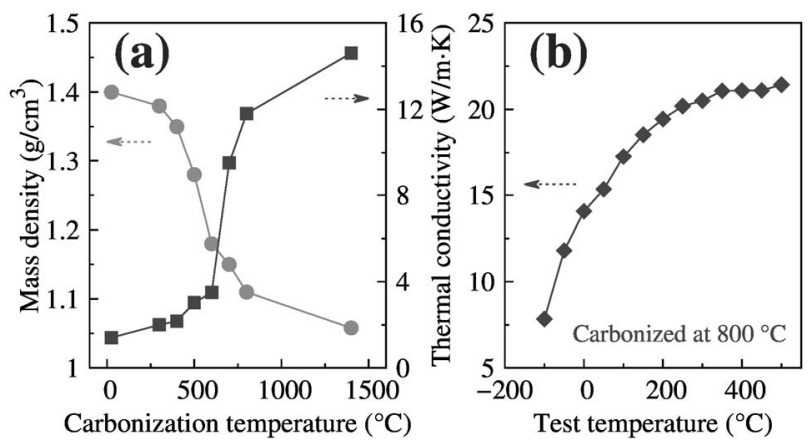

Figure 3. (a) Mass density and thermal conductivity of $\mathrm{C} / \mathrm{C}$ composites carbonized at different temperatures; (b) Thermal conductivity as a function of test temperature for the $\mathrm{C} / \mathrm{C}$ composites carbonized at $800^{\circ} \mathrm{C}$.

Table 1. Thermal diffusivity $(\alpha)$, mass density $(\rho)$, specific heat capacity $\left(C_{p}\right)$, and thermal conductivity $(\kappa)$ for a pure CNT array (referred as CNT), a phenolic matrix (referred as phenolic), a hybrid material after the curing (referred as $\mathrm{C} / \mathrm{C}$ cured), and $\mathrm{C} / \mathrm{C}$ composites carbonized at 500, 800, and $1400^{\circ} \mathrm{C}$ (referred as $\mathrm{C} / \mathrm{C} 500,800$, and 1400 ), respectively. All the values were measured at room temperature.

\begin{tabular}{ccccc}
\hline Sample & $\alpha\left(\mathrm{mm}^{2} / \mathrm{s}\right)$ & $\rho\left(\mathrm{g} / \mathrm{cm}^{3}\right)$ & $C_{p}(\mathrm{~J} / \mathrm{g} \cdot \mathrm{K})$ & $\kappa(\mathrm{W} / \mathrm{m} \cdot \mathrm{K})$ \\
\hline CNT & 9.13 & 0.18 & 0.73 & 1.2 \\
Phenolic & 0.16 & 1.58 & 0.79 & 0.2 \\
C/C cured & 1.2 & 1.4 & 0.83 & 1.4 \\
C/C 500 & 4.85 & 1.28 & 0.49 & 3.04 \\
C/C 800 & 14.2 & 1.11 & 0.75 & 11.8 \\
C/C 1400 & 19.2 & 1.06 & 0.72 & 14.6 \\
\hline
\end{tabular}

$\mathrm{W} / \mathrm{m} \cdot \mathrm{K}$ only after a sufficient pyrolysis above $700^{\circ} \mathrm{C}$. (Notice that $C_{p}$ did not vary greatly while the decrease in $\rho$ drew back the enhancement of $\kappa$, and that for pyrolytic graphite $\alpha=1220 \mathrm{~mm}^{2} / \mathrm{s}$.)

We thus suspect that a high level of graphitization ap peared after the pyrolysis, and that the formation of graphitized pyrolytic carbon allowed more efficient phonon transfers between the CNTs. It is confirmed by calculating the intensity ratio between the $G$ and $D$ Raman peaks $\left(I_{G} / I_{D}\right)$ from the curves shown in Figure 4.

Owning to the abundant functional groups, the impregnation of phenolic resins made it difficult to clearly observe the $G$ and $D$ peaks, like the case for the $\mathrm{C} / \mathrm{C}$ composites carbonized at $400^{\circ} \mathrm{C}$. At higher carbonization temperatures, it was possible to calculate $I_{G} / I_{D}$. The ratio was about 0.4 at the start of pyrolysis at $500^{\circ} \mathrm{C}$, and increased monotonically up to 1.07 and 1.3 after a sufficient pyrolysis at 800 and $1400^{\circ} \mathrm{C}$, respectively. These means the level of graphitization was improved by increasing the carbonization temperature. Furthermore, it was interesting to observe an enhanced $1620 \mathrm{~cm}^{-1}$ peak for the $\mathrm{C} / \mathrm{C}$ composites carbonized at $1400^{\circ} \mathrm{C}$. This peak also indicated the existence of graphite crystals and was

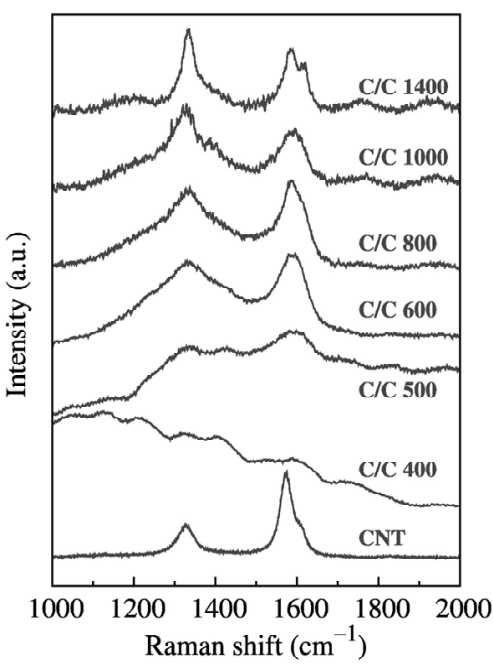

Figure 4. Raman spectra for an untreated CNT array and six $C / C$ composites carbonized at $400,500,600,800,1000$, and $1400^{\circ} \mathrm{C}$, respectively.

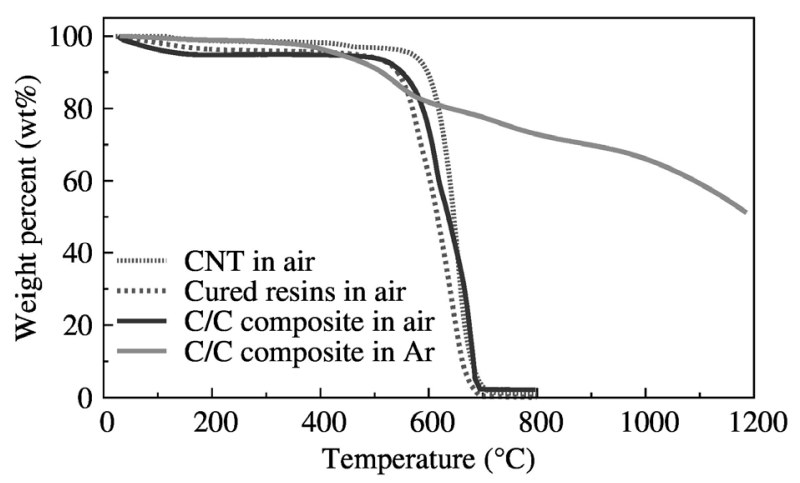

Figure 5. Three TGA curves in air for a CNT array, a pure phenolic matrix after being cured, and a $\mathrm{C} / \mathrm{C}$ composite sample carbonized at $800^{\circ} \mathrm{C}$, and one TGA curve for another carbonized sample in Ar.

also observed in pyrolytic graphite [25].

The curing and carbonization of phenolic matrix within CNT arrays provided the $\mathrm{C} / \mathrm{C}$ composites with high temperature properties. Figure $\mathbf{5}$ shows three thermogravimetric analysis (TGA) curves for different samples in air and one for the $\mathrm{C} / \mathrm{C}$ composite in Ar. The weight loss in air occurred mainly during $550^{\circ} \mathrm{C}-650^{\circ} \mathrm{C}$ for the pure phenolic matrix and the $\mathrm{C} / \mathrm{C}$ composites, while the loss in $\mathrm{Ar}$ was only of $\sim 35 \mathrm{wt} \%$ at $1000^{\circ} \mathrm{C}$. These mean that the $\mathrm{C} / \mathrm{C}$ composites can work at a wide range of temperature. Furthermore, at high temperatures, thermally excited phonons might also facilitate heat transfers. For example, for the composites carbonized at $800{ }^{\circ} \mathrm{C}, \kappa$ increased with the test temperature and saturated to $\sim 21$ $\mathrm{W} / \mathrm{m} \cdot \mathrm{K}$ above $350^{\circ} \mathrm{C}$, see Figure 3(b).

\section{Conclusion}

We report a carbonization method to improve the thermal 
conductivity of CNT arrays. Carbonization converted phenolic matrix into pyrolytic carbon to form $\mathrm{C} / \mathrm{C}$ composites, and enhanced heat transfers between non-neighboring CNTs. The thermal conductivity of $<2 \mathrm{~W} / \mathrm{m} \cdot \mathrm{K}$ for a pure CNT array was significantly improved to 11.8 and $14.6 \mathrm{~W} / \mathrm{m} \cdot \mathrm{K}$ with carbonization at $800^{\circ} \mathrm{C}$ and $1400^{\circ} \mathrm{C}$, respectively. The $\mathrm{C} / \mathrm{C}$ composites showed high thermal stability up to $\sim 550^{\circ} \mathrm{C}$ in air and up to $\sim 1000^{\circ} \mathrm{C}$ in $\mathrm{Ar}$. When working at $500^{\circ} \mathrm{C}$ in $\mathrm{Ar}$, the thermal conductivity was up to $21.4 \mathrm{~W} / \mathrm{m} \cdot \mathrm{K}$.

\section{Acknowledgements}

This work is supported by the National Natural Science Foundation of China (21273269), National Basic Research Program (2010CB934700) by the Ministry of Science and Technology, and International Science \& Technology Cooperation Project (BZ2011049) of Jiangsu Province.

\section{REFERENCES}

[1] S. Berber, Y.-K. Kwon and D. Tománek, "Unusually High Thermal Conductivity of Carbon Nanotubes," Physical Review Letters, Vol. 84, No. 20, 2000, pp. 46134616. doi:10.1103/PhysRevLett.84.4613

[2] P. Kim, L. Shi, A. Majumdar and P. L. McEuen, "Thermal Transport Measurements of Individual Multiwalled Nanotubes," Physical Review Letters, Vol. 87, No. 21, 2001, Article ID: 215502. doi:10.1103/PhysRevLett.87.215502

[3] M. Fujii, X. Zhang, H. Xie, H. Ago, K. Takahashi, T. Ikuta, H. Abe and T. Shimizu, "Measuring the Thermal Conductivity of a Single Carbon Nanotube," Physical Review Letters, Vol. 95, No. 6, 2005, Article ID: 065502. doi:10.1103/PhysRevLett.95.065502

[4] E. Pop, D. Mann, Q. Wang, K. Goodson and H. Dai, "Thermal Conductance of an Individual Single-Wall Carbon Nanotube above Room Temperature," Nano Letters, Vol. 6, No. 1, 2006, pp. 96-100. doi:10.1021/n1052145f

[5] M. J. Biercuk, M. C. Llaguno, M. Radosavljevic, J. K. Hyun, A. T. Johnson and J. E. Fischer, "Carbon Nanotube Composites for Thermal Management," Applied Physics Letters, Vol. 80, No. 15, 2002, pp. 2767-2769. doi:10.1063/1.1469696

[6] C. H. Liu, H. Huang, Y. Wu and S. S. Fan, "Thermal Conductivity Improvement of Silicone Elastomer with Carbon Nanotube Loading," Applied Physics Letters, Vol. 84, No. 21, 2004, pp. 4248-4250. doi:10.1063/1.1756680

[7] T. Morishita, M. Matsushita, Y. Katagiri and K. Fukumori, "A Novel Morphological Model for Carbon Nanotube/Polymer Composites Having High Thermal Conductivity and Electrical Insulation," Journal of Materials Chemistry, Vol. 21, No. 15, 2011, pp. 5610-5614. doi:10.1039/c0jm04007j

[8] A. M. Marconnet, N. Yamamoto, M. A. Panzer, B. L. Wardle and K. E. Goodson, "Thermal Conduction in Aligned Carbon Nanotube-Polymer Nanocomposites with
High Packing Density," ACS Nano, Vol. 5, No. 6, 2011, pp. 4818-4825. doi:10.1021/nn200847u

[9] D. J. Yang, Q. Zhang, G. Chen, S. F. Yoon, J. Ahn, S. G. Wang, Q. Zhou, Q. Wang and J. Q. Li, "Thermal Conductivity of Multiwalled Carbon Nanotubes," Physical Review B, Vol. 66, No. 16, 2002, Article ID: 165440. doi:10.1103/PhysRevB.66.165440

[10] X. J. Hu, A. A. Padilla, J. Xu, T. S. Fisher and K. E. Goodson, "3-Omega Measurements of Vertically Oriented Carbon Nanotubes on Silicon," Journal of Heat Transfer, Vol. 128, No. 11, 2006, pp. 1109-1113. doi:10.1115/1.2352778

[11] Y. Xu, Y. Zhang, E. Suhir and X. Wang, "Thermal Properties of Carbon Nanotube Array Used for Integrated Circuit Cooling," Journal of Applied Physics, Vol. 100, No. 7, 2006, Article ID: 074302. doi:10.1063/1.2337254

[12] S. Shaikh, L. Li, K. Lafdi and J. Huie, "Thermal Conductivity of an Aligned Carbon Nanotube Array," Carbon, Vol. 45, No. 13, 2007, pp. 2608-2613. doi:10.1016/i.carbon.2007.08.011

[13] M. B. Jakubinek, M. Anne White, G. Li, C. Jayasinghe, W. Cho, M. J. Schulz and V. Shanov, "Thermal and Electrical Conductivity of Tall, Vertically Aligned Carbon Nanotube Arrays," Carbon, Vol. 48, No. 13, 2010, pp. 3947-3952. doi:10.1016/j.carbon.2010.06.063

[14] Q. Ngo, B. A. Cruden, A. M. Cassell, G. Sims, M. Meyyappan, J. Li and C. Y. Yang, "Thermal Interface Properties of $\mathrm{Cu}$ filled Vertically Aligned Carbon Nanofiber Arrays," Nano Letters, Vol. 4, No. 12, 2004, pp. 2403 2407. doi:10.1021/n1048506t

[15] M. A. Panzer, G. Zhang, D. Mann, X. Hu, E. Pop, H. Dai and K. E. Goodson, "Thermal Properties of Metal-Coated Vertically Aligned Single-Wall Nanotube Arrays," Journal of Heat Transfer, Vol. 130, No. 5, 2008, Article ID: 052401. doi:10.1115/1.2885159

[16] H. Huang, C. Liu, Y. Wu and S. Fan, "Aligned Carbon Nanotube Composite Films for Thermal Management," Advanced Materials, Vol. 17, No. 13, 2005, pp. 16521656. doi:10.1002/adma.200500467

[17] T. Borca-Tasciuc, M. Mazumder, Y. Son, S. K. Pal, L. S. Schadler and P. M. Ajayan, "Anisotropic Thermal Diffusivity Characterization of Aligned Carbon NanotubePolymer Composites," Journal of Nanoscience and Nanotechnology, Vol. 7, No. 4-5, 2007, pp. 1581-1588. doi:10.1166/jnn.2007.657

[18] W. Lin, K.-S. Moon and C. P. Wong, "A Combined Process of in Situ Functionalization and Microwave Treatment to Achieve Ultrasmall Thermal Expansion of Aligned Carbon Nanotube-Polymer Nanocomposites: Toward Applications as Thermal Interface Materials," Advanced Materials, Vol. 21, No. 23, 2009, pp. 2421-2424. doi:10.1002/adma.200803548

[19] W. Lin, R. Zhang, K.-S. Moon and C. P. Wong, "Molecular Phonon Couplers at Carbon Nanotube/Substrate Interface to Enhance Interfacial Thermal Transport," Carbon, Vol. 48, No. 1, 2010, pp. 107-113. doi:10.1016/i.carbon.2009.08.033

[20] Q.-M. Gong, Z. Li, X.-D. Bai, D. Li, Y. Zhao and J. Li- 
ang, "Thermal Properties of Aligned Carbon Nanotube/ Carbon Nanocomposites," Materials Science and Engineering: A, Vol. 384, No. 1-2, 2004, pp. 209-214. doi:10.1016/j.msea.2004.06.006

[21] H. Li, C. Liu and S. Fan, "Catalyzed Filling of Carbon Nanotube Array with Graphite and the Thermal Properties of the Composites," The Journal of Physical Chemistry $C$, Vol. 112, No. 15, 2008, pp. 5840-5842. doi:10.1021/jp7119697

[22] C. Singh, M. S. P. Shaffer, K. K. K. Koziol, I. A. Kinloch and A. H. Windle, "Towards the Production of LargeScale Aligned Carbon Nanotubes," Chemical Physics Letters, Vol. 372, No. 5-6, 2003, pp. 860-865. doi:10.1016/S0009-2614(03)00531-1
[23] K. A. Trick and T. E. Saliba, "Mechanisms of the Pyrolysis of Phenolic Resin in a Carbon/Phenolic Composite," Carbon, Vol. 33, No. 11, 1995, pp. 1509-1515. doi:10.1016/0008-6223(95)00092-R

[24] C.-L. Liu, W.-S. Dong, J.-R. Song and L. Liu, "Evolution of Microstructure and Properties of Phenolic Fibers during Carbonization," Materials Science and Engineering: A, Vol. 459, No. 1-2, 2007, pp. 347-354. doi:10.1016/j.msea.2007.02.067

[25] R. J. Nemanich and S. A. Solin, "First- and Second-Order Raman Scattering from Finite-Size Crystals of Graphite," Physical Review B, Vol. 20, No. 2, 1979, pp. 392-401. doi:10.1103/PhysRevB.20.392 